\title{
Optical Dispersion Characteristics of Polyvinyl Alcohol Reinforced with a Nanoceramic Filler
}

\author{
ANDREEA IRINA BARZIC1, MARIUS SOROCEANU' ${ }^{1}$, RAZVAN ROTARU $^{1, *}$, \\ VALERIA HARABAGIU ${ }^{1}$, ROMEO CRISTIAN CIOBANU ${ }^{2}$ \\ 1 "Petru Poni" Institute of Macromolecular Chemistry, 41A Grigore Ghica Voda Alley, 700487, Iasi, Romania \\ ${ }^{2}$ SC All Green SRL, 8 George Cosbuc Str. 700470, Iasi, Romania
}

\begin{abstract}
Polymer films with high refractive index are suitable for a wide range of applications, such as optical fibers, lens and other components for optoelectronic devices. In this work, polyvinyl alcohol films were prepared from aqueous solutions, which were homogenized by ultrasonication. In order to increase the refractive index, the polymer was reinforced with barium titanate nanoparticles, which are previously ultrasonicated for an adequate dispersion inside the host polymer. The dispersion of the refractive index in visible domain was analyzed as a function of filler percent introduced in polymer, showing that an increase in sample's polarizability determined an increase in the refractive index values. The reinforcement caused a decrease of Abbe number indicating a higher light dispersion in the samples. Optical dispersion parameters were extracted from dispersion curves, revealing a reduction of band gap from $3.448 \mathrm{eV}$ for pure polymer to $2.605 \mathrm{eV}$ for the sample containing 2\% barium titanate. Doping with the ceramic nanofiller determined a increase in optical conductivity and real part of dielectric constant as a result of appearance of new level states in the band gap. The increase of third order nonlinear optical susceptibility and nonlinear refractive index indicates the suitability of the analyzed nanocomposites for nonlinear optics applications.
\end{abstract}

Keywords: polyvinyl alcohol, barium titanate, nanocomposites, refractive index, light dispersion.

\section{Introduction}

Polymeric materials have known a growing evolution, in the past decades, as a result of the necessity to optimize their balance of properties for specific applications. Significant breakthroughs were offered by the nanotechnologies in the development of nanocomposites that have proved high technological potential in numerous industries [1-3]. In other words, the incorporation of inorganic nanoparticles in a polymer matrix determined great achievements in the properties of the reinforced material [4,5]. Optical and dielectric characteristics of polymer nanocomposites (PNCs) have received a particular attention because of their importance in manufacturing components for optoelectronic devices, such as antireflection coatings [6], holographic optical elements [7], radiation shielding layers [8], encapsulants for light emitting diodes or solar cells [9], waveguides [10] etc. However, besides the numerous advantages of PNCs, the low value of refractive index (n) limits their some optical uses where high-n is needed [11]. Therefore, depending on the pursued technological area, the choice of the adequate inorganic nanofiller is also crucial. There are many types of high refractive index dopants, such as $\mathrm{ZnS}$ and $\mathrm{ZrO}_{2}$ [12, 13], $\mathrm{TiO}_{2}$ (rutile, anatase or brookit phase) [11] and $\mathrm{BaTiO}_{3}$ [14]. The latter is shown to be less photocatalytic than $\mathrm{TiO}_{2}$, but it has superior refractive index $\left(\mathrm{n}_{\mathrm{D}}=2.40\right)$ comparatively with $\mathrm{ZrO}_{2}$ $\left(\mathrm{n}_{\mathrm{D}}=2.16\right)$ [14]. Also, $\mathrm{BaTiO}_{3}$ (white powder), is a ferroelectric inorganic material from the perovskite class with a high permittivity, which is widely investigated for its photorefractive effects [15] and piezoelectric properties [16]. From this point of view, it can be used in passive and active electronics components, sensors, electro-optic devices, thermistors, electromagnetic shields or in biomedical application [17].

\footnotetext{
*email: rotaru.razvan@icmpp.ro
} 
The polyvinyl alcohol (PVA) is one of the most popular synthetic polymers, known for its water solubility, odorless, optical transparency, noncorrosive, and biocompatible properties. In addition, this eco-friendly thermoplastic polymer exhibits excellent film forming capability combined with good adhesion features. For these reasons, many researchers started to upgrade the optical performance of PVA by insertion of different additives. Abdullah and Saber [18] prepared PVA/ $\mathrm{NiCl}_{2}$ films and studied the effect of PNC composition on optical parameters revealing a decrease in band gap value upon doping and a small increase in $n$ value. Mahendia et al [19] investigated the optical performance of PVA containing various amounts of citrate-stabilized Au nanoparticles and obtained a n value of about 1.59 at $520 \mathrm{~nm} . \mathrm{TiO}_{2}$ in PVA gave rise to a composite of $\mathrm{n} \sim 1.517$ at $589 \mathrm{~nm}$ [20]. In another study, Mahendia and co-workers [21] introduced metal nanoparticles in PVA and observed an increase of $\mathrm{n}$ at $589 \mathrm{~nm}$ up to $\sim 1.75$ for PVA/Cu and $\sim 1.58$ for PVA/Ag. Banerjee et al [22] filled PVA with $\mathrm{MnCl}_{2}$ and obtained sunflower-like assembled pattern and a n value around 1.70 at $589 \mathrm{~nm}$. Other studies were focused on doping PVA to display specific dielectric or magnetic characteristics [23-26]. One of the main advantages of PVA-based materials resides in the facile processing into components for optical devices, such as optical waveguides and optical image storage system [22].

The objective of this investigation was to analyze linear and nonlinear optical characteristics of PVA doped with nanoceramic filler. For this purpose, $\mathrm{BaTiO}_{3}$ nanoparticles were dispersed in PVA host by ultrasonication. The $\mathrm{n}$ dispersion was discussed as a function of introduced filler percent. Optical dispersion parameters were obtained by applying single effective oscillator model, revealing the effect of $\mathrm{BaTiO}_{3}$ amount on the band gap. Dielectric constant at optical frequencies and optical conductivity were also evaluated. The nonlinear optical parameters, like third-order susceptibility and nonlinear refractive index were determined through Miller's rule, which involves the linear optical parameters to examine the suitability of the prepared PNCs for application in nonlinear optical and photonic devices.

\section{Materials and methods}

\subsection{Materials}

Poly(vinyl alcohol) (PVA), 99-100\% hydrolyzed, was purchased from Acros Organics and used as received. According to the provider, the polymer has an number average molecular weight of $\mathrm{Mn}=$ 124,000. The precursors for barium titanate, titanium dioxide (Chemical Company, 98\% purity) and barium carbonate (Sigma-Aldrich, 99\% purity) were also used as received.

Barium titanate $\left(\mathrm{BaTiO}_{3}\right.$; $\left.\mathrm{BT}\right)$ was prepared by using a modified solid-state reaction described in a previous work [17]. Shortly, a 1/2 (w/w) titanium dioxide / barium carbonate mixture was ultrasonicated in Milli-Q ultrapure water $(60 \mathrm{~mL})$ for $60 \mathrm{~min}(119 \mathrm{~kJ}$ were dissipated and the temperature exceeded $92^{\circ} \mathrm{C}$ ). The obtained powder was further decanted and dried in a microwave furnace for 10 minutes. The last step was the thermal treatment for 3 hours, performed in a laboratory furnace at temperatures of $500^{\circ} \mathrm{C}$.

For the preparation of PVA/BT composites, a stock polymer solution was first obtained by dissolving $5 \mathrm{~g}$ of PVA in $250 \mathrm{ml}$ of deionized water at room temperature. PVA/BT composites of different composition $\left(0.5,1\right.$ and $\left.2 \mathrm{wt} \% \mathrm{BaTiO}_{3}\right)$ were prepared by ultrasonication of mixture of $50 \mathrm{~mL}$ of PVA solution and BT particles for 20 minutes, when $36.5 \mathrm{~kJ}$ energy was dissipated) and the temperature increased from 20 to $94^{\circ} \mathrm{C}$. Finally the mixtures were poured onto glass plates (Petri dishes of diameter $10 \mathrm{~cm}$ ) and the obtained films were dried in air at room temperature.

\subsection{Methods}

The thickness of the film samples was measured using a digital micrometer (Insize Co., LTD, Spain) and the average values are presented in Table 1. Standard deviation is $\pm 0.01 \mathrm{~mm}$. Four samples were considered for each thickness measurement.

The refractive index of the PVA/BT nanocomposites was measured on a Abbe multi-wavelength refractometer DR-M4 type (Atago Co., Ltd., Japan) at $486 \mathrm{~nm}, 589 \mathrm{~nm}, 656 \mathrm{~nm}$ and $670 \mathrm{~nm}$. 
The transmittance of films at the same measuring wavelengths was recorded on a SPECORD 210 PLUS (Analytik Jena, Germany) spectrophotometer.

The ultrasonication experiments were performed with an Sonics Vibracell ultrasound generator (750 $\mathrm{W}$ nominal electric power, $20 \mathrm{kHz}$ ultrasound frequency, provided with a display giving the energy delivered to the end of the probe and a sensor for temperature). A microwave heating facility ( $800 \mathrm{~W}$ electric power, 2,5 GHz microwave frequency) and a Vulcan A 130 laboratory oven were used for the drying and the thermal treatment of BT powder, respectively.

\section{Results and discussions}

\subsection{Refractive index and optical dispersion parameters}

The refractive index values for the pure and filled PVA films were determined by means of refractometry at room temperature $\left(23^{\circ} \mathrm{C}\right)$. The obtained values are listed in Table 1 , together with the transmittance at $600 \mathrm{~nm}$ of each examined nanocomposite film. For all samples the refractive index decreases as the wavelength of incident light increases. Embedding $\mathrm{BaTiO}_{3}$ nanoparticles in $\mathrm{PVA}$ matrix induces an increase of the refractive index, at all measuring wavelengths, via enhancing the reinforcement degree with respect to the pure PVA. So, according to the Lorentz-Lorenz relation, the $\mathrm{n}$ follows the same trend. For instance, at $589 \mathrm{~nm}$, the magnitude of $\mathrm{n}$ increases from 1.50 for pure PVA up to 1.57 , when the filler amount reaches $2 \%$. Similar variation of $n$ values was reported by Mahendia et al [19] for PVA doped with citrate-stabilized Au nanoparticles. Such increase in refractive index value could be also attributed to an increase in density of the nanocomposite. Banerjee et al [22] showed that reinforcement of PVA determined an increase in chain packing generated by strong interaction between the filler and PVA.

Table 1. The transmittance of the prepared samples, film thickness (d), refractive index (n) at several wavelengths and Abbe number (V)

\begin{tabular}{|c|c|c|c|c|c|c|c|}
\hline \multirow{2}{*}{ Sample code } & \multirow{2}{*}{$\begin{array}{c}\text { Transmittance at } \\
600 \mathrm{~nm}, \%\end{array}$} & \multirow{2}{*}{$\begin{array}{c}\mathrm{d}, \mathrm{mm} \\
( \pm 0.01)\end{array}$} & \multicolumn{4}{|c|}{$\mathrm{n}$} & \multirow[t]{2}{*}{$\mathrm{V}$} \\
\hline & & & $486 \mathrm{~nm}$ & $589 \mathrm{~nm}$ & $656 \mathrm{~nm}$ & $670 \mathrm{~nm}$ & \\
\hline PVA/ $0 \% \mathrm{BaTiO}_{3}$ & 91 & 0.11 & 1.52 & 1.50 & 1.49 & 1.49 & 16.67 \\
\hline $\mathrm{PVA} / 0.5 \% \mathrm{BaTiO}_{3}$ & 53 & 0.13 & 1.55 & 1.53 & 1.51 & 1.51 & 13.25 \\
\hline PVA/ $1 \% \mathrm{BaTiO}_{3}$ & 31 & 0.14 & 1.58 & 1.55 & 1.53 & 1.52 & 11.00 \\
\hline $\mathrm{PVA} / 2 \% \mathrm{BaTiO}_{3}$ & 10 & 0.16 & 1.62 & 1.57 & 1.56 & 1.55 & 9.50 \\
\hline
\end{tabular}

The light dispersion is very important when using the prepared PNCs in modern technologies like optical fibers. The variation of $\mathrm{n}$ with wavelength is essential since it affects the functional role of optical fiber [22]. The dispersion properties allow the controlling the cross-talking during transmission in optical fiber and concomitantly restrains the information carrying capacity. An essential parameter that describes the dispersion properties of materials is Abbe number (V), which is defined as follows:

$$
V=\frac{n_{589}-1}{n_{486}-n_{656}}
$$

where $n$ denotes the refractive index and the subscript numbers refer to the photon wavelength.

A low value of Abbe number is related to high dispersion and vice-versa [27]. Therefore, the analysis of Abbe number is very useful when designing optical fibers, lens and other optics items. For the studied samples, the calculated $\mathrm{V}$-values were found to slightly decrease as the $\mathrm{BaTiO}_{3}$ percent is higher. Thus, according to the values of Abbe number the studied samples follow the following inequality: PVA/2\%BT < PVA/1\%BT < PVA/0.5\%BT < PVA. In other words, the optical dispersion values of all filled PVA films are higher than that of the pristine PVA matrix.

Having in view this background from Abbe number analysis, the optical dispersion parameters are further extracted from Wemple and DiDomenico (WDD) model [28] depicted by equation (2):

$$
\mathrm{n}^{2}=\frac{\mathrm{E}_{0}^{2}-(\mathrm{hv})^{2}+\mathrm{E}_{\mathrm{d}} \mathrm{E}_{0}}{\mathrm{E}_{0}^{2}-(\mathrm{h} v)^{2}}
$$


where $\mathrm{h}$ represents the Planck's constant, $v$ is the frequency, $\mathrm{E}_{0}$ denotes the single-oscillator energy for electronic transitions and $\mathrm{E}_{\mathrm{d}}$ is the dispersion energy.

Figure 1(a) presents the graphs of $1 /\left(\mathrm{n}^{2}-1\right)$ versus $(\mathrm{h} v)^{2}$ for PVA matrix and its $\mathrm{BaTiO}_{3}$-based nanocomposites. The values of $\mathrm{E}_{0}$ and $\mathrm{E}_{\mathrm{d}}$ were computed from the slope and intercept values of linear dependencies depicted in Figure 1(a) and the results are given in Table 2. According to WDD model [28], $E_{d}$ is linked to the strength of the interband optical transitions, whereas $E_{0}$ provide information on the average energy band gap, which is the half of its value. The oscillator energy ranges in a similar manner as the optical band gap energy. It can be noticed that the band gap values are lowered as the nanoceramic filler amount increases in the PVA matrix. The data concerning $E_{0}$ and $E_{d}$ are further used to evaluate the static refractive index $\left(\mathrm{n}_{0}\right)$ at zero photon energy, as described by equation (3):

$$
n_{0}=\sqrt{1+\frac{E_{d}}{E_{0}}}
$$

Table 2. The values of the dispersion energy $\left(E_{d}\right)$, single-oscillator energy $\left(E_{0}\right)$, band gap energy $\left(E_{g}\right)$, average oscillator energy $\left(S_{0}\right)$, average interband oscillator wavelength $\left(\lambda_{0}\right)$ and static refractive index $\left(\mathrm{n}_{0}\right)$ :

\begin{tabular}{|c|c|c|c|c|c|c|}
\hline \multirow{2}{*}{ Sample code } & $\mathrm{E}_{\mathrm{d}}(\mathrm{eV})$ & $\mathrm{E}_{0}(\mathrm{eV})$ & $\mathrm{E}_{\mathrm{g}}(\mathrm{eV})$ & $\mathrm{S}_{0}(\mathrm{~m})^{-2}$ & $\lambda_{0}(\mathrm{~nm})$ & $\mathrm{n}_{0}$ \\
\hline $\mathrm{PVA} / 0 \% \mathrm{BaTiO}_{3}$ & 7.797 & 6.896 & 3.448 & $3.477 \cdot 10^{-14}$ & 180 & 1.459 \\
\hline $\mathrm{PVA} / 0.5 \% \mathrm{BaTiO}_{3}$ & 7.221 & 6.182 & 3.091 & $2.893 \cdot 10^{-14}$ & 201 & 1.473 \\
\hline $\mathrm{PVA} / 1 \% \mathrm{BaTiO}_{3}$ & 6.410 & 5.455 & 2.728 & $2.270 \cdot 10^{-14}$ & 228 & 1.476 \\
\hline $\mathrm{PVA} / 2 \% \mathrm{BaTiO}_{3}$ & 6.420 & 5.210 & 2.605 & $2.171 \cdot 10^{-14}$ & 238 & 1.493 \\
\hline
\end{tabular}
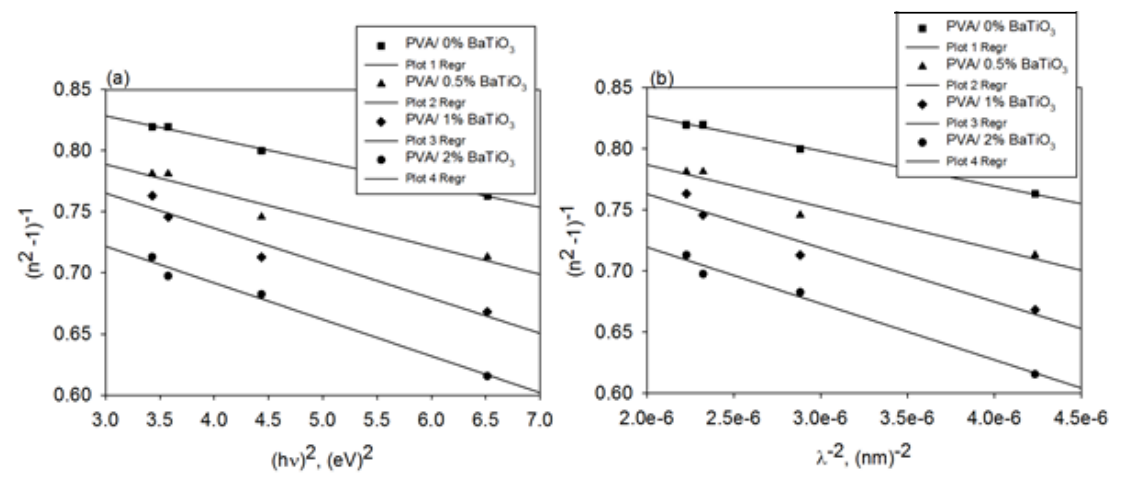

Figure 1. The variation of $1 /\left(\mathrm{n}^{2}-1\right)$ with $(\mathrm{hv})^{2}(\mathrm{a})$ and $1 /\left(n^{2}-1\right)$ with $\lambda^{-2}(b)$ for the studied PNCs.

Based on Sellmeier dispersion theory [29], one may understand the normal dispersion behavior of $n$ in the wavelength domain of maximum transparency. According to this approach, the material is imagined as being composed of a collection of atoms, which lead to polarized oscillating dipoles in the presence of the oscillating electric field of the light. This model assumes that at higher wavelengths, these dipoles become in resonance with the incident light frequency and, therefore, the material presents almost no absorption [19]. The single term Sellmeier oscillator model equation is presented below:

$$
\begin{gathered}
\frac{n_{\infty}^{2}-1}{n^{2}-1}=1-\left(\frac{\lambda_{0}}{\lambda}\right)^{2} \\
\mathrm{n}_{\infty}^{2}=1+\mathrm{S}_{0} \lambda_{0}^{2}
\end{gathered}
$$

where $\mathrm{n}_{\infty}$ is the long wavelength refractive index, $\lambda_{\mathrm{o}}$ is the average interband oscillator wavelength and $\mathrm{S}_{0}$ is the average oscillator strength.

By plotting $1 /\left(n^{2}-1\right)$ versus $\lambda^{-2}$ one may estimate from the values of intercept and slope the $\lambda_{0}$ and $\mathrm{S}_{0}$. For the analyzed PVA nanocomposites these plots are depicted in Figure 1(b) and the results are listed $n$ Table 2. The reinforcement of PVA with ceramic nanoparticles determines a slight decrease in average oscillator energy values, while the average interband oscillator wavelength increases. The obtained $S_{0}$ and $\lambda_{o}$ values are of the same order with those reported for other polymer materials [30]. 


\subsection{Dielectric constant and optical conductivity}

The real $\left(\varepsilon_{\mathrm{r}}\right)$ and imaginary $\left(\varepsilon_{\mathrm{i}}\right)$ parts of the dielectric constant at optical frequencies can be evaluated based on refractive index and extinction coefficient $(k)$, using equations (6) and (7) $[28,29]$ :

$$
\begin{aligned}
& \varepsilon_{r}=n^{2}-k^{2} \\
& \varepsilon_{i}=2 n k
\end{aligned}
$$

where extinction coefficient, $\mathrm{k}$, depends on the absorption coefficient $\alpha$ as follows: $\mathrm{k}=\alpha \lambda / 4 \pi$.

For all examined films the values of $\alpha$ were obtained based on transmittance at similar wavelengths with those involved in refractometry experiments. The variation of $\varepsilon_{\mathrm{r}}$ and $\varepsilon_{\mathrm{i}}$ with photon energy is shown in Figure 2. The magnitude of $\varepsilon_{\mathrm{r}}$ is much higher than that of $\varepsilon_{\mathrm{i}}$ because the first one is mainly affected by the square value of $\mathrm{n}$, while the second one is more impacted by $\mathrm{k}$ value. Also, it can be noticed that the real part of dielectric constant increases with photon energy, whereas the imaginary part is almost constant in the studied optical energy domain. The values of both real and imaginary parts of the optical dielectric constant increase with addition of a higher percent of $\mathrm{BaTiO}_{3}$ in $\mathrm{PVA}$ matrix.
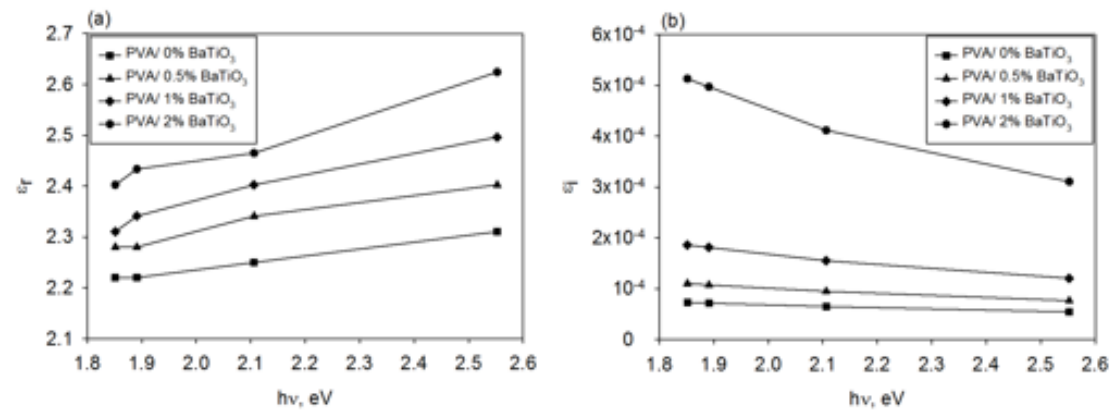

Figure 2. The variation of real (a) and imaginary (b) parts of the optical dielectric constant with photon energy for the studied PNCs

The optical conductivity is related to the refractive index, $n$, and the absorption coefficient, $\alpha$. For all studied materials this optical parameter was estimated using equation (8):

$$
\sigma_{\text {opt }}=\alpha \cdot n \cdot c / 4 \pi
$$

where $\sigma_{o p t}$ is the optical conductivity and $\mathrm{c}$ is the speed of light in empty space.

Optical conductivity is a measure of the material's optical response as a result of the charge carrier motion in the presence of incident electromagnetic waves. Figure 3 depicts the variation of $\sigma_{o p t}$ with photon energy for the pure PVA and $\mathrm{PVA} / \mathrm{BaTiO}_{3}$ samples. The optical conductivity of the PVA matrix is almost constant in the range of 1.8-2.6 eV. The same trend is observed for the samples containing $0.5 \%$ and $1 \% \mathrm{BaTiO}_{3}$. When the filler amount reaches $2 \%$, a slight decrease in optical conductivity with photon energy is noticed. The addition of ceramic nanoparticles determines an increase of optical conductivity with respect to the pure polymer matrix. This could be ascribed to the fact that new states appear in the band gap and allow easier movement of electrons to travel from valence to the nearest state as remarked in the decrease of optical band gap (see Table 2).

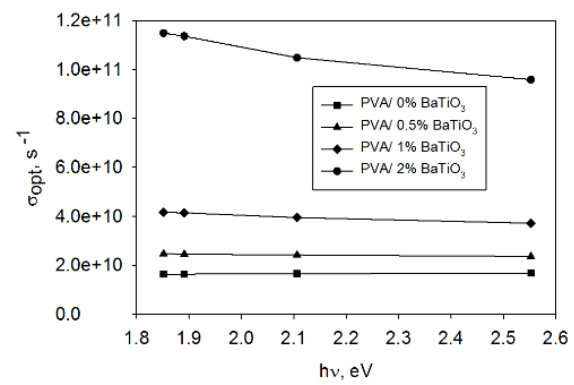

Figure 3. Optical conductivity against photon energy for the studied PNCs.

\subsection{The nonlinear optical parameters}

For specific optical applications, one should evaluate the nonlinear optical parameters like susceptibility and refractive index. The linear optical susceptibility of the material is linked to the singleoscillator energy and dispersion energy as shown in equation (9): 


$$
\chi^{(1)}=\frac{E_{d} / E_{0}}{4 \pi}
$$

where $\chi^{(1)}$ is the linear optical susceptibility.

The results for $\chi^{(1)}$ are presented in Table 3, indicate a slight increase with reinforcement percent. Based on $\chi^{(1)}$ and the energies extracted from WDD model [28], one can further determine the nonlinear third order optical susceptibility according to equation (10):

$$
\chi^{(3)}=A \cdot\left(\chi^{(1)}\right)^{4}=6.82 \cdot 10^{-15} \cdot\left(E_{d} / E_{o}\right)^{4} \text { (e.s.u.) }
$$

where $\chi^{(3)}$ is the third order optical susceptibility and $\mathrm{A}$ is a constant, which has a value of $1.7 \cdot 10^{-10}$ (e.s.u.).

The nonlinear refractive index $\left(\mathrm{n}_{2}\right)$ is evaluated from $\chi^{(3)}$ and static refractive index, as indicated by the relation (11):

$$
n_{2}=\frac{12 \pi \chi^{(3)}}{n_{0}}
$$

The data concerning the nonlinear optical parameters are displayed in Table 3. It was found that the addition of ceramic nanofiller in PVA produces an increase in third order optical susceptibility nonlinear refractive index. These aspects confirm the suitability of the $\mathrm{PVA} / \mathrm{BaTiO}_{3}$ nanocomposites for nonlinear optical and photonic devices.

Table 3. The values of the linear optical susceptibility $\left(\chi^{(1)}\right)$, third order optical susceptibility $\left(\chi^{(3)}\right)$ and nonlinear refractive index $\left(\mathrm{n}_{2}\right)$ :

\section{Conclusions}

\begin{tabular}{|c|c|c|c|}
\hline Sample code & $\chi^{(1)}$ & $\chi^{(3)}$ (e.s.u.) & $\mathrm{n}_{2}$ (e.s.u.) \\
\hline $\mathrm{PVA} / 0 \% \mathrm{BaTiO}_{3}$ & 0.090 & $1.115 \cdot 10^{-14}$ & $1.972 \cdot 10^{-13}$ \\
\hline $\mathrm{PVA} / 0.5 \% \mathrm{BaTiO}_{3}$ & 0.093 & $1.270 \cdot 10^{-14}$ & $2.205 \cdot 10^{-13}$ \\
\hline $\mathrm{PVA} / 1 \% \mathrm{BaTiO}_{3}$ & 0.094 & $1.300 \cdot 10^{-14}$ & $2.247 \cdot 10^{-13}$ \\
\hline $\mathrm{PVA} / 2 \% \mathrm{BaTiO}_{3}$ & 0.098 & $1.572 \cdot 10^{-14}$ & $2.656 \cdot 10^{-13}$ \\
\hline
\end{tabular}

Polymer nanocomposite films were prepared by dispersing barium titanate in PVA through ultrasonication and drying. They were characterized for application in optoelectronics. The reinforcement agent produced modification of light dispersion through the samples. As the ceramic filler percent increases from $0 \%$ to $2 \%$, one may notice an increase of the refractive index from 1.50 to 1.57 at $589 \mathrm{~nm}$. The reinforcement also generated a reduction of the Abbe number values, revealing a higher light dispersion in the filled polymer films. The band gap is lowered by addition of the ceramic nanoparticles from $3.448 \mathrm{eV}$ for pure polymer to $2.605 \mathrm{eV}$ for the sample containing $2 \%$ barium titanate. Optical conductivity and real part of dielectric constant are enhanced by embedding barium titanate, which leads to appearance of new states in the forbidden band gap. The increased third order nonlinear optical susceptibility and nonlinear refractive index values are arguments for the suitability of the PVA$\mathrm{BaTiO}_{3}$ nanocomposites in nonlinear optics applications.

Acknowledgement: This work was supported by a grant of the Romanian Ministry of Research and Innovation, PCCDI-UEFISCDI, project number PN-III-P1-1.2-PCCDI-2017-0428/PCCDI/2018, contract no. 40PCCDI, within PNCDI III. The financial support of European Social Fund for Regional Development, Competitiveness Operational Programme Axis 1 - Project "Petru Poni Institute of Macromolecular Chemistry - Interdisciplinary Pol for Smart Specialization through Research and Innovation and Technology Transfer in Bio(nano)polymeric Materials and (Eco)Technology ", InoMatPol (ID P_36_570, Contract 142/10.10.2016, cod MySMIS: 107464) is also gratefully acknowledged. One of the co-authosrs, R.C.C, also acknowledges the support of NANO-REV-EM-ASAM Project / Competitiveness Operational Programme 2014-2020, under grant ID P\_37\757, cod my SMIS: 104089, nr. 119/16.09.2016.

This article was presented at Polymer Processing in Engineering Conference - PPE 2019, 7- 9 October 2019, Galati - Romania. 


\section{References}

1. BADAMSHINA, E., GAFUROVA, M., J. Mater. Chem., 22, 2012, p. 9427-943.

2.BARZIC, R.,F,, BARZIC A.,I., DUMITRASCU, GH., Polym. Compos., 35, 2014, 8, p. 1543-1552. 3.KONONOVA,V., S., GUBANOVA, N., G., KORYTKOVA, N., E., SAPEGIN, A., D., SETNICKOVA, K., etrychkovych, R., Uchytil, P., Polym. Nanocompos. Membr. Appl. Sci., 8, 2018, 7, p. 1181.

4.EFTIMIE TOTU, E., CRISTACHE, C.,E., VOICILA, E., OPREA, O., AGIR I., TAVUKCUOGLU, O., DIDILESCU, A.,C., I., Mater. Plast., 54, 2017, 4, p.666-672.

5.PETREA, C.,M., GARDEA, S.,A,, IOVU H., Mater. Plast., 45, 2008, 1, p. 34-37.

6.LIN, T.,X., CHEN, K.,J., CHEN P.,Y., JAN, J.,S., ACS Appl. Nano Mater., 1, 2018, 2 p.741-750.

7.MITSUBE K., NISHIMURA Y., NAGAYA K., TAKAYAMA S., TOMITA Y., Opt. Mater. Express, 4, 2014, 5, p. 982-996.

8.SRINIVASAN, K., JAMES JABASEELAN SAMUEL, E., J. Med. Phys., 42, 2017, 4, p.273-278.

9.TOPOLNIAK, I., CHAPEL, A., GAUME, J., BUSSIERE, PO., CHADEYRON, G., GARDETTE, JL., THERIAS, S., Polym. Degrad. Stabil., 145, 2017, p. 52-59.

10.SIGNORETTO, M., SUÁREZ, I., CHIRVONY, V., S., ABARGUES, R., RODRÍGUEZ-CANTÓ, P., J., MARTÍNEZ-PASTOR, J., Nanotechnology, 26, 2015, 47, p. 475201.

11.LIU, B.T., TANG, S.J., YU, YY., LIN, S.H., Colloids Surf., A 377, 2011, p. 138-143

12.WANG, B., WILKES, G., J. Polym. Sci., A, 29, 1991, p. 905-909.

13.LEE, S., SHIN, H,-J., YOON, S.-M., VI, D., CHOI, J.-Y., PAIK, U., J. Mater. Chem., 18, 2008, p.1751-1755.

14.IMAI, Y., TERAHARA, A., HAKUTA, Y.. MATSUI, K., HAYASHI, H., UENO, N., Polym.. J., 42, 2010, 2, p. 179-184.

15.FEINBERG, J., HEIMAN, D., TANGUAY, A. R., HELLWARTH, R. W., J. Appl. Phys., 51, 1980, 3 p.1297-1305.

16.ACOSTA, M., NOVAK, N., ROJAS, V., PATEL, S., VAISH, R., KORUZA, J., ROSSETTI, G. A., RÖDEL, J., Appl. Phys. Rev., 4, 2017, 4, p. 041305.

17.ROTARU, R., PEPTU, C., SAMOILA, P., HARABAGIU, V., J. Am. Ceram. Soc., 100, 2016, 10, p. 4511-4518.

18.ABDULLAH, O. G., SABER, D. R., Appl. Mechan. Mater., 110-116, 2012, p. 177-182.

19.MAHENDIA, S., TOMAR, A. K., CHAHAL, R. P., GOYAL, P., KUMAR, S., J. Phys. D: Appl. Phys., 44, 2011, 20, p. 205105.

20.YOVCHEVA, T., VLAEVA, I., BODUROV, I., DRAGOSTINOVA, V., SAINOV, S., Appl. Opt., 51, 2012, 32, p.7771-7775.

21.MAHENDIA, S., TOMAR, A. K., GOYAL P. K., KUMAR, S., J. Appl. Phys., 113, 2013, 7, p. 073103.

22.BANERJEE, M., JAIN, A., MUKHERJEE, G. S., Polym. Compos., 40, 2019, E765-E775.

23.ZIDAN, HM., J Appl Polym Sci, 88, 2003, 1, p. 104-111.

24.BANERJEE, M., SACHDEV, P.. MUKHERJEE, G. S. , J. Appl. Phys. 111, 2012, 9, p.094302

25.SACHDEV, P., BANERJEE, M., MUKHERJEE, G., Defence Sci. J., 64, 2014, p. 290-294.

26.BHAJANTRI, R. F., RAVINDRACHARY, V., HARISHA, A., RANGANATHAIAH, C., KUMARASWAMY, G. N., Appl. Phys. A, 87, 2007, 4, p. 797-805.

27.CUI, Z., LÜ, C., YANG, B., SHEN, J., SU, X., YANG, H., Polymer, 42, 2001, 26, p. 10095-10100. 28.didomenico, M., Wemple, S. H., J. Appl. Phys. 40, 1969, 2, p.720-734.

29.SELLMEIER, W., Ann. Phys. Chem., 143, 1871, p.271.

30.HulubeI, C., AlBU, R. M., LISA, G., NICOlESCU, A., HAMCIUC, E., HAMCIUC, C., BARZIC, A. I., Solar Energy Mater. Solar Cells, 193, 2019, p. 219-230.

Manuscript received: 24.02 .2020 